Попова Евгения Михайловна

аспирант кафедры финансов

Байкальского государственного университета

\section{НАЛОГОВЫЙ КРЕДИТ КАК ИНСТРУМЕНТ РЕГУЛИРОВАНИЯ РЕГИОНАЛЬНОГО ИНВЕСТИЦИОННОГО ПРОЦЕССА: ЗАРУБЕЖНЫЙ ОПЫТ}

Popova Evgeniya Mikhailovna

PhD student, Finance Department, Baikal State University

\section{TAX CREDIT AS A TOOL OF REGIONAL INVESTMENT PROCESS REGULATION: INTERNATIONAL PRACTICE}

\begin{abstract}
Аннотация:
Практика государственного регулирования регионального инвестиционного процесса отличается широким арсеналом налоговых инструментов, среди которых особое место принадлежит инвестиционному налоговому кредиту. За рубежом на данный инструмент существует достаточно высокий спрос, в то время как отечественные инвесторы не рассматривают его в качестве налоговый льготы. Сложившаяся ситуация объясняется явным противоречием между капиталоемкими проектами, реализация которых и дает право на получение кредита, и недостатком финансовых ресурсов, образующимся у предприятий за счет неисполненных в установленный срок налоговых обязательств. В то же время изучение нормативно-правовой базы и результатов применения налогового кредита в разных штатах США позволило сделать вывод, что преимущественное использование полнообъемных невозмещаемых налоговых кредитов способствует достижению главной цели рассматриваемой льготы, состоящей в высвобождении дополнительных финансовых ресурсов для осуществления инвестиционной деятельности.
\end{abstract}

Ключевые слова:

налоговый кредит, косвенное субсидирование, инвестиционный процесс, финансовые ресурсы, капитальные вложения, целевой сектор, налог на корпоративный доход, регчон.

\section{Summary:}

State regulation of regional investment process is characterized by a wide set of tax tools among which a special place belongs to an investment tax credit. There is a strong demand for a tax credit abroad but it is not considered as a tax preference by Russian investors. It can be explained by the apparent contradiction between capital-intensive project which is a reason for getting a tax credit and few financial resources being generated as a result of not fulfilled tax liabilities on time. Simultaneously, the study of tax legislative and tax credit practice in the USA shows that extensive use of nonrefundable volume-based tax credits meets the main goal of this preference which is granting financial resources for investment.

Субсидирование экономической деятельности через налоговую систему представляет собой рыночный подход к решению проблемы недостаточной инвестиционной активности. Для России наиболее интересен опыт применения налоговых стимулов в странах с фредеративным устройством, поскольку используемые за рубежом механизмы могут быть эффективно адаптированы к отечественной практике регулирования инвестиционных процессов на региональном уровне. Одним из таких государств, где накоплен достаточно большой, а главное - положительный, опыт, являются США. Мы изучили нормативно-правовую базу по предоставлению инвестиционного налогового кредита (далее - ИНК) в разных штатах. Выбор данной налоговой льготы был продиктован, с одной стороны, ее широким применением (в большинстве штатов) и сравнительно высокой эффрективностью, а с другой - отсутствием спроса на рассматриваемый инструмент среди российских инвесторов. В отечественной литературе практически не встречаются работы, посвященные детальному изучению зарубежной практики реализации налогового кредита именно на уровне отдельных территориальных единиц. В связи с этим наше исследование было направлено на выявление ключевых особенностей предоставления налогового кредита в зарубежной практике регулирования региональных инвестиционных процессов в целях установления причин его невостребованности в российских субъектах.

По крайней мере в 33 штатах реализуется одна программа и более, в которых предлагаются налоговые кредиты при осуществлении реальных инвестиций. Хотя кредиты предоставляются и по налогу на имущество, и по корпоративному франшизному налогу, однако их максимальная часть приходится на налог на корпоративный доход, что главным образом связано с наиболее значительными налоговыми обязательствами, возникающими по данному налогу. Изучение опыта применения налоговых кредитов на уровне отдельных штатов позволило выделить 
приоритетные направления экономической деятельности и сектора, чья инвестиционная активность стимулируется посредством налоговых инструментов.

В качестве приоритетных направлений можно выделить проведение научных исследований и повышение эффективности производства. К ключевым сегментам относят сельское хозяйство, промышленное производство, строительство, телекоммуникационные услуги, чистую и альтернативную энергетику. Как показывает мировой опыт, крайне редко налоговые кредиты предоставляются предприятиям розничной торговли или проектам в области добычи полезных ископаемых. Однако в экономически отсталых районах торговля также может рассчитывать на государственную поддержку. Налоговые кредиты в сфрере добычи применяются в штате Техас, одной из отраслей специализации которого является нефтегазовая отрасль. Их можно разделить на две категории. К первой относятся налоговые кредиты при добыче природного газа или нефти из низкоэффективных скважин. Потенциальный размер ссуды в этом случае не определяется. Например, низкоэффективной скважина признается, если в течение 3 месяцев среднедневной объем добычи нефти составил менее 15 баррелей. Абсолютная величина налогового кредита исчисляется путем умножения налогового обязательства по налогу на добычу нефти на ставку кредита. При этом если цена за 1 баррель была в интервале между 25 и 30 долл., то применяется ставка кредита в $25 \%$, если между 22 и 25 долл., то в 50 \%, если менее 22 долл., то в 100 \% [1]. Ко второй категории относится налоговый кредит, предоставляемый при использовании оборудования, повышающего эффективность добычи нефти. Оборудование должно быть включено в программу нефтяных разработок, которая утверждается профильным институтом штата. При этом механизмы должны обеспечивать снижение энергии, используемой при добыче нефти, более чем на 10 \% в расчете на 1 баррель. В штате Флорида каждые 3 года Агентство по развитию предпринимательства проводит исследования и рекомендует приоритетные виды экономической деятельности, в свою очередь включающие высокоэффективные и целевые секторы (производство полупроводников, транспортных средств, высокоточных механизмов, чистая энергетика).

Почти все налоговые кредиты, предоставляемые на уровне штатов, являются полнообъемными, поскольку их размер определяется исходя из общей величины произведенных предприятием расходов. Исключение составляют исследовательские налоговые кредиты, относящиеся к категории приростных, когда кредит исчисляют исходя из приращения расходов за определенный период. При этом стоит заметить, что приростные налоговые кредиты в настоящее время используются достаточно редко и в основном для стимулирования инвестиций в научные разработки. Изначально конструкция приростного налогового кредита была нацелена на стимулирование инвестиций в исследования, которые не были бы сделаны при его отсутствии. Это достигалось посредством признания не всех расходов, а только в части превышения заранее установленной величины (базы). Другими словами, базовая величина есть сумма инвестиций, которые предприятия осуществили бы и без налогового кредита. Примером подобной формы может служить исследовательский кредит, применяемый в штате Техас. Признаваемые расходы определяются как разница между фактическими расходами в текущем году и 50 \% от средней суммы расходов за 3 предшествующих года [2].

Практика применения налогового кредита в отдельных штатах показывает, что в большинстве он ограничивается 50 \% налогового обязательства по налогу на доход или корпоративный франшизный налог. Сроки использования кредита варьируют от 5 до 20 лет. Также ряд налоговых кредитов включает требования по созданию дополнительных рабочих мест. В соответствии с порядком предоставления налогового кредита для поддержки производителей (штат Нью-Мексико) должно быть создано как минимум одно рабочее место из расчета на каждые 500 тыс. долл. стоимости оборудования. Данное условие обязательно для проектов, совокупный объем инвестиций по которым составляет менее 30 млн долл.; для проектов с объемом инвестиций свыше этой суммы должно быть организовано одно рабочее место в расчете на каждый миллион стоимости оборудования [3]. Обязательным пунктом предоставления налогового кредита на капитальные затраты для высокоэффективных и целевых секторов (штат Флорида) является создание минимум 100 новых рабочих мест.

Как отмечено ранее, ключевая роль налоговых льгот состоит в привлечении инвестиций в те сфреры, где наблюдается их недостаток. В свою очередь инвестиционная активность во многом определяется доступностью финансовых ресурсов. Именно на снижение стоимости фринансирования инвестиционных расходов нацелен налоговый кредит. Например, в штате Миссисипи в рамках Программы по поддержке аграрного сектора экономики предоставляется налоговый кредит, который позволяет снизить стоимость заемных ресурсов, привлекаемых для финансирования инвестиций: налоговые обязательства могут быть уменьшены на величину процентов, уплачиваемых по корпоративным облигациям [4].

В качестве другого примера того, как налоговый кредит способствует концентрации финансовых ресурсов для последующего инвестирования в целевые сферы, можно привести налоговый кредит на инвестиции в акции, выпущенные Организацией по содействию финансовому раз- 
витию территорий, который широко применяется как на федеральном уровне, так и на региональном. Порядок его предоставления мы сочли достаточно интересным, в связи с чем предлагаем рассмотреть его более подробно: сначала по федеральному налогу на корпоративный доход, а затем по налогу на доход, взимаемый штатом Миссисипи, поскольку процедура его получения на уровне отдельного штата во многом дублирует порядок, установленный на фредеральном уровне.

Организация по содействию финансовому развитию территорий заключает соглашение о распределении с Фондом фринансовых институтов отсталых (развивающихся) районов, созданным при Минфине США, в отношении налоговых кредитов по фредеральному налогу на доход. Цель фонда состоит в расширении возможностей экономического роста в тех районах, где финансовая инфраструктура недостаточно развита. Инструментом для достижения этой цели является реализация Программы по предоставлению налоговых кредитов для развития «новых рынков» (New Markets Tax Credit Program). При этом в ее рамках налоговый кредит предоставляется не гражданам и предприятиям, а аккредитованным финансовым посредникам, так называемым организациям по содействию фринансовому развитию территорий. Они в свою очередь выпускают акции и размещают их среди инвесторов. Стимулом для покупки акций выступают полученные данными организациями налоговые кредиты, которые они в обмен на вложения в их акции предоставляют инвесторам. Приобретенные кредиты инвесторы используют для снижения собственных налоговых обязательств. Ставка по кредиту составляет 5 \% от суммы первоначальных инвестиций в первые 3 года, 6 \% - в последние 4 года. Например, к распределению организация получила 1 млн долл., это значит, что общая сумма кредита за 7 лет составит 390 тыс. долл.

Эти специализированные организации функционируют на местном уровне и выступают посредниками при предоставлении займов, вложений в уставный капитал предприятий и оказании иных финансовых услуг. Согласно действующим правилам данные компании в первый год получения права на продажу налогового кредита должны инвестировать в реальный бизнес в отсталых районах не менее 85 \% от привлеченных средств и поддерживать этот уровень на протяжении 6 последующих лет. В свою очередь, чтобы получить финансовую поддержку от организаций, предприятия должны соответствовать следующим требованиям: 1) не менее 50 \% валового дохода должно быть получено от ведения бизнеса в экономически отсталом районе; 2) не менее 40 \% движимого имущества фрирмы должно быть задействовано на территории такого района [5].

Программа по предоставлению налоговых кредитов для развития «новых рынков» признается успешной, так как спрос на налоговые кредиты опережает предложение. Всего за 14 лет действия проекта с 2002 г. от организаций по содействию финансовому развитию территорий в Фонд финансовых институтов отсталых (развивающихся) районов была подана 3481 заявка на сумму 314,6 млрд долл., а удовлетворены только 1032 заявки на сумму 50,5 млрд долл., или 29,6 \%. Организации по содействию фринансовому развитию территорий привлекли более 42,8 млрд долл. Они инвестировали 41,9 млрд долл. в предприятия, расположенные в экономически отсталых районах. Их общее количество составило 5458 [6]. Инвестиции были направлены на строительство многофункциональных имущественных комплексов, развитие альтернативной энергетики, производства и торговли.

На уровне штата реализуется региональный аналог Программы по предоставлению налоговых кредитов для развития «новых рынков». Организации по содействию финансовому развитию территорий подают заявки в Агентство по развитию штата Миссисипи для получения кредитов по налогам, взимаемым штатом: налогу на корпоративный доход, корпоративному франшизному налогу. Агентство выдает свидетельство, дающее компании право на получение кредита. Организация по содействию финансовому развитию территорий может подать заявку до фрактического размещения акций. В этом случае ей выдается сертификат на оценочную сумму кредита, которая основана на ожидаемом объеме инвестиций, указанном в заявлении. Сумма кредита по налогу на корпоративный доход, взимаемый штатом, определяется как 8 \% от одной трети ожидаемой величины средств, планируемых к привлечению в результате размещения акций среди инвесторов. Ожидаемая величина исчисляется как среднегодовое значение привлеченных организацией средств через продажу акций за 3 прошлых года. Однако компания должна разместить акции среди инвесторов в течение 60 дней с даты предоставления кредита, иначе теряет на него право. При этом если реальный объем привлеченных инвестиций оказался ниже оценочного значения, первоначальный размер налогового кредита корректируется. Как и по федеральной программе, как минимум 85 \% средств, привлеченных от размещения акций, должны быть инвестированы в предприятия, функционирующие в экономически отсталых районах.

В свою очередь, кроме установления верхнего предела фактически получаемого налогового кредита, существуют дополнительные условия, которые нацелены на создание еще больших налоговых послаблений и снижение налогового бремени для тех, кто осуществляет значительные инвестиционные расходы или расходы в наименее экономически развитых районах. Самым распространенным условием подобного рода является требование к минимальному объему инвестиций. Например, по налоговому кредиту на инвестиции в промышленный сектор (штат 
Миссисипи) минимальный объем инвестиций составляет 1 млн долл., по налоговому кредиту, стимулирующему повышение эффрективности производства (штат Айдало), - 500 тыс. долл., по налоговому кредиту на капитальные затраты для высокоэффективных секторов (штат Флорида) - 25 млн долл., а по налоговому кредиту на капитальные затраты для целевых секторов (штат Флорида) - 100 млн долл. При этом хотелось бы отметить, что, несмотря на значительный разброс в минимальной сумме, ставка по налоговому кредиту составляет около 5 \%.

Следующий дополнительный стимул - прогрессивная шкала ставок по налоговому кредиту. Например, в соответствии с порядком предоставления налогового кредита, стимулирующего использование широкополосных технологий (штат Миссисипи), все округа ранжируются по трем уровням на основе показателей доходов на душу населения и безработицы. Если инвестиции осуществляются в округе, относящемся к третьему уровню (наименее развитые), то кредит предоставляется по ставке в $15 \%$, если ко второму уровню (средний уровень развития) - $10 \%$, наконец, первому уровню (высокий) - 5 \%.

Другой стимул, аналогичный предыдущему, - установление прямой зависимости между объемом инвестиций и верхним лимитом налогового кредита. Так, ежегодный кредит на капитальные затраты для высокоэффрективных секторов (штат Флорида) не может превышать определенной доли от налогового обязательства по налогу на корпоративный доход. Если инвестиции в проект составили минимум 100 млн долл., то налоговое обязательство может быть снижено до нуля; если инвестиции оказались больше чем 50 млн, но меньше чем 100 млн, то налоговый кредит не может превышать 75 \% от величины налогового обязательства; если инвестиции меньше 50 млн, то налоговый кредит ограничивается 5 \% от величины налогового обязательства [7].

Наконец, некоторые налоговые кредиты предусматривают использование расчетных формул, учитывающих темпы роста инвестиций и занятости, что представляет собой более гибкий подход к регулированию инвестиционной активности посредством налоговых инструментов. Исчисленные значения выступают основой для определения максимального размера фактически получаемого налогового кредита. Заметим, что в рассмотренных случаях верхний предел фрактического налогового кредита фрикировался заранее в законодательном порядке. Например, в конструкцию налогового кредита, предоставляемого в рамках Программы по поддержке аграрного сектора экономики (штат Миссисипи), встроен механизм в форме оценочного коэффициента ETVP, содержащий стимулирующую составляющую: чем выше темп прироста реальных инвестиций и создаваемых рабочих мест, тем больше величина налогового кредита. Коэфффициент ETVP рассчитывается на ежегодной основе и умножается на общую сумму налогового обязательства, таким образом определяется максимальный размер налогового кредита, который предприятие может получить в текущем году (формула (1)):

$$
\operatorname{ETVP}=\frac{T_{1} \times 2+T_{2}}{3}
$$

где $\quad T_{1}-$ темп прироста числа рабочих мест,

$T_{2}$ - темп прироста реальных инвестиций, т. е. чем больше значение коэффициента, тем на лучшие кредитные условия может рассчитывать предприятие.

В заключение следует сделать два важных вывода. Во-первых, рассмотренные примеры наглядно демонстрируют значение налогового кредита в создании необходимой концентрации финансовых ресурсов в приоритетных секторах и направлениях экономического развития. Преимущественное использование невозмещаемых налоговых кредитов объясняется их большим стимулирующим потенциалом. Посредством установления верхнего предела, как правило - в процентах от налогового обязательства, и реализуется стимулирующая роль налоговых инструментов: чем больше доход, генерируемый проектом, тем выше налоговые обязательства, а значит, и фрактически получаемый ежегодный кредит. Другими словами, чем более эффективным оказывается проект, тем на больший объем фрактически получаемого налогового кредита он может рассчитывать. Таким образом увязывается экономическая и бюджетная эффективность.

Во-вторых, ключевая причина низкого спроса на отечественный налоговый кредит по сравнению с зарубежными аналогами состоит в слабой увязке цели и порядка его предоставления, который есть не что иное, как способ достижения цели. Напомним, что ИНК предоставляется по налогам, по которым не возникают значительные налоговые обязательства, а с учетом установленного предела в 50 \% на уменьшение текущих платежей по соответствующим налогам ИНК не способен формировать у компаний значительные финансовые ресурсы. Таким образом, величина высвобождаемых денежных ресурсов не может оказать серьезное стимулирующее воздействие, в особенности на те наукоемкие виды деятельности, которые перечислены в основаниях предоставления ИНК. Наконец, в силу наличия более гибких альтернативных инструментов сами регионы в конкурентной борьбе за привлечение инвесторов проявляют слабый интерес к налоговому кредиту и предпочитают использовать налоговые каникулы или снижение налоговой ставки. 


\section{Ссылки:}

1. Investing in Texas: Economic Incentives and Programs [Электронный ресурc]. URL: http://www.ttara.org/files/document/file-54f083d474aad.pdf (дата обращения: 30.03.2018).

2. Ibid.

3. Mankiw N.G., Weinzierl M.C., Yagan D.F. Optimal taxation in theory and practice [Электронный ресурc] // Journal of Economic Perspectives. 2009. Vol. 23 (4). P. 147-174. URL: https://dash.harvard.edu/bitstream/handle/1/4263739/mankiw_optimaltaxationtheory.pdf?sequence=2 (дата обращения: 30.03.2018).

4. Mississippi Tax Incentives, Exemptions and Credits [Электронный ресурс] / Department of Revenue. URL: http://www.dor.ms.gov/Individual/Documents/2013IncentiveBook-pdffinal.pdf (дата обращения: 30.03.2018).

5. Introduction to the New Markets Tax Credit Program [Электронный ресурс] / Washington: Community Development Financial Institutions Fund. URL: https://www.cdfifund.gov/Documents/2017\%20Introduction\%20to\%20NMTC\%20Program\%20Presentation\%20For\%20Release.pdf (дата обращения: 30.03.2018).

6. Ibid.

7. Review of the Capital Investment Tax Credit [Электронный ресурс] // Florida: Budget Subcommittee on Finance and Tax. URL: https://www.flsenate.gov/PublishedContent/Session/InterimReports/2015-204ft.pdf (дата обращения: 30.03.2018).

\section{References:}

Introduction to the New Markets Tax Credit Program 2018, Washington: Community Development Financial Institutions Fund, viewed 30 March 2018, <https://www.cdfifund.gov/Documents/2017\%20Introduction\%20to\%20NMTC\%20Program\%20Presentation\%20For\%20Release.pdf>.

Investing in Texas: Economic Incentives and Programs 2018, viewed 30 March 2018, <http://www.ttara.org/files/document/file-54f083d474aad.pdf>.

Mankiw, NG, Weinzierl, MC \& Yagan, DF 2009, 'Optimal taxation in theory and practice', Journal of Economic Perspectives, vol. 23 (4), pp. 147-174, viewed 30 March 2018, <https://dash.harvard.edu/bitstream/handle/1/4263739/mankiw_optimaltaxationtheory.pdf?sequence=2>, https://doi.org/10.1257/jep.23.4.147.

Mississippi Tax Incentives, Exemptions and Credits 2018, Department of Revenue, viewed 30 March 2018, <http://www.dor.ms.gov/Individual/Documents/2013IncentiveBook-pdffinal.pdf>.

'Review of the Capital Investment Tax Credit', 2018, Florida: Budget Subcommittee on Finance and Tax, viewed 30 March 2018, <https://www.flsenate.gov/PublishedContent/Session/InterimReports/2015-204ft.pdf> 